\title{
A Periacetabular Osteotomy for the Treatment of Severe Dysplastic Hips
}

\author{
Hirotaka Karashima MD, Masatoshi Naito PhD, \\ Kei Shiramizu PhD, Takahiko Kiyama PhD, \\ Akira Maeyama PhD
}

Received: 26 April 2010/ Accepted: 23 September 2010/Published online: 9 October 2010

(C) The Association of Bone and Joint Surgeons (B) 2010

\begin{abstract}
Background We believe a curved periacetabular osteotomy is indicated for treatment of severe dysplastic hips with center-edge angles less than $0^{\circ}$, classified as Severin Group IV-b. However, the lower limit of the center-edge angle in hips classified as Severin Group IV-b is not clearly defined to determine which patients should receive periacetabular osteotomy alone.

Questions/purposes We retrospectively compared the results of curved periacetabular osteotomies performed for the treatment of severe (Severin Group IV-b: center-edge angle $<0^{\circ}$ ) and moderate (Severin Groups III and IV-a: center-edge angle $\geq 0^{\circ}$ ) dysplastic hips. We investigated the lower limit of the center-edge angle, which was corrected by a curved periacetabular osteotomy alone in Severin Group IV-b hips.

Patients and Methods We divided 191 hips in 163 patients into moderate (147 hips) and severe (44 hips) dysplastic hip groups. Minimum followup was 2 years (mean, 70.9 and 70.6 months, respectively). Clinical evaluations were performed using the Harris hip score.

Each author certifies that he/she has no commercial associations (eg, consultancies, stock ownership, equity interest, patient/licensing arrangements, etc) that might pose a conflict of interest in connection with the submitted article.

Each author certifies that his or her institution approved the human protocol for this investigation, that all investigations were conducted in conformity with ethical principles of research, and that informed consent for participation in the study was obtained
\end{abstract}

H. Karashima ( $\varangle)$, M. Naito, K. Shiramizu, T. Kiyama,

A. Maeyama

Department of Orthopaedic Surgery, Fukuoka University

School of Medicine, 7-45-1 Nanakuma,

Jonan-ku, Fukuoka 814-0180, Japan

e-mail: hirotaka_karashima@hotmail.co.jp
Radiographic measurements included the center-edge angle, acetabular head index, acetabular roof obliquity, and head lateralization index. Complications were compared between the two groups.

Results All clinical and radiographic postoperative parameters showed satisfactory improvement over the preoperative parameters in both groups. The postoperative acetabular roof obliquity and head lateralization index were equivalent between the two groups. Eleven hips deteriorated to end-stage osteoarthritis. No complications were specifically associated with the severe dysplastic hips.

Conclusions Curved periacetabular osteotomy alone for treatment of severe dysplastic hips with preoperative center-edge angles as low as $-20^{\circ}$ and classified as Severin Group IV-b restored weightbearing area and medialization. Level of Evidence Level III, therapeutic study. See Instructions for Authors for a complete description of the levels of evidence.

\section{Introduction}

Periacetabular osteotomy is a well-established surgical treatment for early-stage osteoarthritis caused by dysplastic hips. Curved periacetabular osteotomy (CPO) [15], which is a modified Bernese periacetabular osteotomy [7], has been indicated for patients with symptomatic dysplastic hips with lateral center-edge (CE) angles less than $16^{\circ}$ measured on AP radiographs.

At our institution, severe dysplastic hips are defined as those with $\mathrm{CE}$ angles less than $0^{\circ}$, according to the Severin classification for Group IV-b [18, 23]. Patients with proper joint congruency observed on the preoperative AP radiograph of the hip at maximum abduction were indicated for CPO without using additional techniques. This treatment 
was chosen because the acetabular fragment was easy to move and reposition, and the size of the gap at the osteotomy surface could be minimized with the curvilinear C-shaped osteotomy [15, 21]. Nozawa et al. [17] and Shindo et al. [19] used a periacetabular osteotomy with a bone graft for the treatment of severe dysplastic hips classified as Severin Group V. Clohisy et al. [3, 4] and Ninomiya [16] used a periacetabular osteotomy with some additional techniques, such as osteotomy of the proximal femur, release of the joint capsule, and adductor tenotomy, for patients classified as having Severin Groups IV and V hips. Based on previous reports, we assumed the treatment for dislocated hips classified as Severin Group V may require additional techniques to reposition the hip. However, a previous report did not specify the lower limit of the $\mathrm{CE}$ angle for periacetabular osteotomy alone and whether additional techniques were required in the treatment of Severin Group IV-b hips.

We aimed to assess the effectiveness of the CPO as treatment for hips with severe acetabular dyplasia defined as Severin Group IV-b. We asked the following questions: (1) Did postoperative clinical parameters, assessed by the Harris hip score (HHS) of severe dysplastic hips classified as Severin Group IV-b and treated by CPO alone achieve equivalent results compared with those obtained in moderate dysplasia? (2) Does the CPO correct preoperative radiographic measures of dysplasia in severe dysplastic (SD) and in moderate dysplastic (MD) hips without other techniques, such as bone grafting at the osteotomy site of the ilium, release of the joint capsule, or adductor tenotomy? (3) Is there a difference in progression of Tönnis grade of osteoarthritis after the CPO in SD hips compared with MD hips? (4) How does the incidence of complications compare when $\mathrm{CPO}$ is used to treat SD hips in comparison to MD hips?

\section{Patients and Methods}

We retrospectively reviewed 237 hips in 203 patients, comprising 182 women and 21 men who had undergone a CPO from August 1995 to September 2006. All patients presented with symptoms of hip dysplasia for at least 3 months, with intact joint congruency observed on an AP radiograph of the hip at maximum abduction. We used the Severin classification system $[18,23]$ to define the severity of the adult dysplastic hips, which frequently is used to evaluate radiographic results for surgical treatment of children with developmental dysplasia of the hip. In this classification system, SD hips originally were defined as having a $\mathrm{CE}$ angle less than $0^{\circ}$ and were categorized as Severin Group IV-b. Accordingly, we defined SD hips as Severin Group IV-b in this study. The cases in this study were divided into a MD hip group (MD group) with dysplastic hips with $\mathrm{CE}$ angles of $0^{\circ}$ or greater and classified as Severin Groups III and IV-a and a SD hip group (SD group) with subluxated hips with $\mathrm{CE}$ angles less than $0^{\circ}$ and classified as Severin Group IV-b. The MD group comprised 147 hips in 130 patients, and the SD group comprised 44 hips in 43 patients. Ten patients had a MD hip on one side and a SD hip on the other side. Accordingly, we evaluated these 191 hips in 163 patients, comprising 148 women and 15 men with a minimum followup of 2 years. Patients were excluded from the study if they had undergone previous surgery, had extreme femoral head deformity such as Legg-Calvé-Perthes disease, or were not observed for at least 2 years after the surgery. CPO procedures were performed at the Fukuoka University School of Medicine's Department of Orthopaedic Surgery on only three hips classified as Severin Group V. Owing to our inexperience in treating this type of dysplasia, we also excluded them and limited our investigation to Severin Group IV-b hips. The mean $( \pm \mathrm{SD})$ ages of the patients at the time of surgery for the MD and SD groups were $36.5 \pm 12.1$ and $36.4 \pm 10.2$ years, respectively, and the mean durations of followup for the MD and SD groups were $70.9 \pm 31.1$ and $70.6 \pm 38.9$ months, respectively (Table 1). Although the number of patients was different between the two groups, the gender ratio, the mean age at $\mathrm{CPO}$, and the mean duration of followup were not different. This study was approved by the Institutional Review Board. All patients gave informed consent before their participation.

All surgical procedures were performed by the senior author (MN). To confirm the joint congruency again, fluoroscopic examination was performed in the operating room before surgery. For the $\mathrm{CPO}$, the direct anterior approach was used for surgical exposure as previously described [15]. The lateral femoral cutaneous nerve was dissected free from the surrounding connective tissues. The anterior superior iliac spine (ASIS) was osteotomized with the inguinal ligament and sartorius muscle attached and then retracted medially with the lateral femoral cutaneous nerve and neurovascular bundle. To preserve the blood supply to the acetabular fragment, the gluteus muscles were

Table 1. Patient data

\begin{tabular}{lllll}
\hline Factor & MD group & SD group & p Value & Power \\
\hline $\begin{array}{l}\text { Number of hips } \\
\text { Gender }\end{array}$ & 147 & 44 & & \\
$\quad$ (males:females) & $12: 135$ & $4: 40$ & 0.8455 & 0.0559 \\
Age at surgery (years)* & $36.5 \pm 12.1$ & $36.4 \pm 10.2$ & 0.9275 & 0.0503 \\
Followup (months)* & $70.9 \pm 31.1$ & $70.6 \pm 38.9$ & 0.9605 & 0.0503 \\
\hline
\end{tabular}

*Values are expressed as mean $\pm \mathrm{SD} ; \mathrm{MD}=$ moderately dysplastic; $\mathrm{SD}=$ severely dysplastic. 
not stripped from the iliac bone. In this approach, the skin incision was relatively small, approximately $9 \mathrm{~cm}$, and the damage caused by soft tissue dissection was limited because the abductors were left intact. As the first step in the osteotomy, a C-shaped osteotomy line was marked using an airtome from the proximal part of the anterior inferior iliac spine to the distal part of the quadrilateral surface, and an osteotomy line also was marked at a point just medial to the iliopubic eminence of the superior ramus of the pubis. After the osteotomy line was checked with intraoperative fluoroscopy, an osteotomy of the quadrilateral surface was performed using a curved chisel. The elevator then was introduced into the space between the distal joint capsule and the psoas tendon. When the tip of the elevator contacted the ischium, the chisel was inserted along the elevator, and the direction of the blade toward the infracotyloid groove was confirmed using intraoperative fluoroscopy. Although the body of the ischium was not visible, this region could be palpated and confirmed using intraoperative fluoroscopy. The chisel was hammered a few centimeters into the ischium. Finally, the superior ramus of the pubis was osteotomized using a curved chisel with a rounded end. To reorient the acetabular fragment, one hook was inserted at the osteotomy site proximal to the anteroinferior iliac spine and drawn distally. Another hook was attached to the osteotomy site on the superior pubic ramus and drawn proximomedially. If the acetabular fragment failed to reorient, the hip was moved into external rotation and abduction in a figure-four maneuver. The curvilinear $\mathrm{C}$-shaped osteotomy enabled smooth acetabular reorientation and medialization because the osteotomy surfaces had the same curvatures. The acetabular fragment was reoriented to obtain adequate coverage of the femoral head and then fixed with two or three poly-L-lactic acid screws or titanium cannulated cancellous screws. The osteotomized ASIS was adjusted to its original position and fixed with two titanium cannulated cancellous screws. These titanium screws were removed 3 months after surgery.

Active motion exercises were initiated on the first postoperative day. Partial weightbearing $(10 \mathrm{~kg})$ using two crutches or a walker was allowed on the third postoperative day, and full weightbearing was allowed after 8 weeks postoperatively.

Clinical evaluations were performed using the HHS [8]. Radiographic measurements included the CE angle [24], acetabular head index (AHI) [9], acetabular roof obliquity (ARO) [12], and head lateralization index (HLI) [25]. The severity of the secondary osteoarthrosis was graded using the Tönnis classification system [22]. Complications related to the CPO were investigated and compared between the two groups.

All radiographic measurements were made three times on different occasions by three authors (HK, TK, AM) who were blind to the clinical results, and the average values were calculated. The measurements then were analyzed for intraobserver and interobserver reliability. The intraclass correlation coefficients of these measurements were 0.96 to 0.99 for intraobserver variances and 0.95 to 0.98 for interobserver variance.

The Mann-Whitney $\mathrm{U}$ test was used to compare the corresponding clinical results and radiographic measurements between the two groups. The Wilcoxon rank test was used to compare the preoperative and postoperative parameters in each subgroup. Fisher's exact test was used for the gender proportion and osteoarthritis grade proportion between two groups. Significance was defined as $p$ values less than 0.05 . Post hoc power analysis comparing the clinical evaluation and radiographic measurements of the two groups showed the statistical evaluation of this study was proper.

\section{Results}

Regardless of the degree of dysplasia, the HHS of both groups improved by the latest followup. The mean HHS of the MD group improved $(\mathrm{p}<0.0001)$ from $73.9 \pm 14.2$ points preoperatively to $94.3 \pm 5.7$ points postoperatively, whereas that of the SD group improved $(\mathrm{p}<0.0001)$ from $76.7 \pm 12.5$ points preoperatively to $94.7 \pm 5.2$ points postoperatively (Table 2 ).

The mean values of all the postoperative radiographic parameters (CE angle, AHI, ARO, and HLI) showed

Table 2. Comparison of the clinical scores and radiographic parameters between the groups

\begin{tabular}{lcccc}
\hline Parameter & MD group & \multicolumn{1}{l}{ SD group } & p Value & Power \\
\hline Harris hip score (points) & & & \\
Preoperative & $73.9 \pm 14.2$ & $76.7 \pm 12.5$ & 0.2037 & 0.2273 \\
Postoperative & $94.3 \pm 5.7$ & $94.7 \pm 5.2$ & 0.7187 & 0.0705 \\
Center-edge angle $\left(^{\circ}\right)$ & & & \\
Preoperative $\quad 8.9 \pm 5.6$ & $-6.6 \pm 4.4$ & $<0.0001$ & 1.0000 \\
Postoperative & $32.6 \pm 8.1$ & $28.4 \pm 7.4$ & 0.0018 & 0.8845 \\
Acetabular head index & & & \\
Preoperative $\quad 61.0 \pm 6.8$ & $44.3 \pm 4.7$ & $<0.0001$ & 1.0000 \\
Postoperative & $84.0 \pm 7.7$ & $80.1 \pm 7.3$ & 0.0032 & 0.8533 \\
Acetabular roof obliquity $\left({ }^{\circ}\right.$ ) & & & \\
Preoperative & $23.8 \pm 6.7$ & $34.1 \pm 5.7$ & $<0.0001$ & 1.0000 \\
Postoperative & $7.0 \pm 6.1$ & $8.3 \pm 5.0$ & 0.1678 & 0.2775 \\
Head lateralization index & & & \\
Preoperative & $59.4 \pm 7.2$ & $63.8 \pm 5.1$ & 0.0002 & 0.9842 \\
Postoperative & $57.6 \pm 8.5$ & $58.4 \pm 6.3$ & 0.5008 & 0.0959 \\
\hline
\end{tabular}

*Values are expressed as mean $\pm \mathrm{SD} ; \mathrm{MD}=$ moderately dysplastic; $\mathrm{SD}=$ severely dysplastic. 
improvements $(p<0.0001)$ compared with those of the preoperative parameters in both groups. The mean CE angle in the MD group improved $(\mathrm{p}<0.0001)$ from $8.9^{\circ} \pm 5.6^{\circ}$ preoperatively to $32.6^{\circ} \pm 8.1^{\circ}$ postoperatively, whereas that in the SD group improved $(\mathrm{p}<0.0001)$ from $-6.6^{\circ} \pm 4.4^{\circ}$ preoperatively to $28.4^{\circ} \pm 7.4^{\circ}$ postoperatively. The change in the mean CE angle in the MD group was $23.7^{\circ}$, whereas that in the SD group was $35.0^{\circ}$. The change in the $\mathrm{CE}$ angle was larger $(\mathrm{p}<0.0001)$ in the SD group than in the MD group and similar to the change in the AHI $(p<0.0001)$. Although the mean postoperative CE angle and $\mathrm{AHI}$ in the SD group were slightly inferior to those in the MD group, the mean postoperative ARO and HLI values did not differ between the two groups $(p=0.1678,0.5008)$. The minimum preoperative CE angle in the SD group was $-20^{\circ}$ in this study (Fig. 1). Additional techniques, such as bone grafting, release of the joint
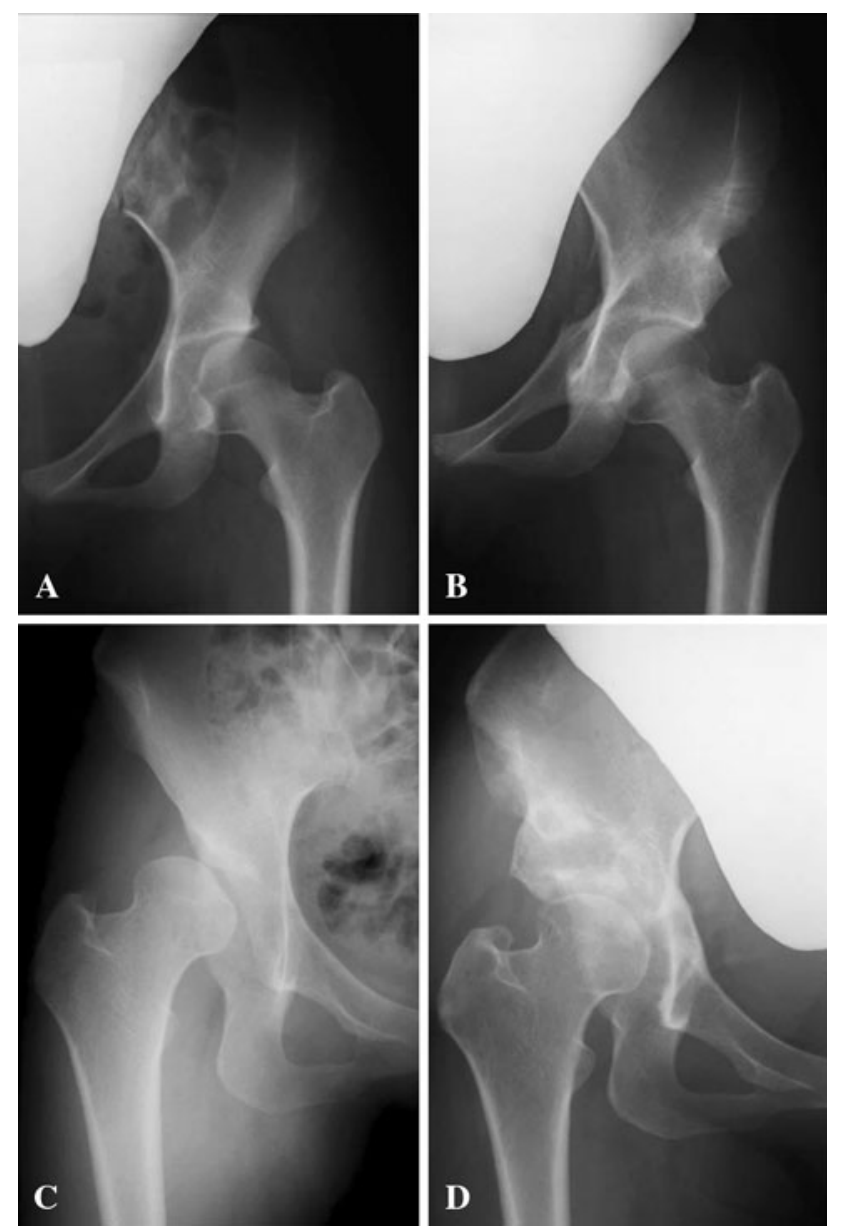

Fig. 1A-D Preoperative radiographs show (A) a MD hip with a CE angle of $8^{\circ}$ and (C) a SD hip with a minimum CE angle of $-20^{\circ}$. Postoperative radiographs of the (B) MD and (D) SD hips show coverage of the femoral head and medialization have been obtained. capsule, and adductor tenotomy, were not required for SD hips classified as Severin Group IV-b in this study.

In the followup period, 167 hips $(87.4 \%)$ maintained their preoperative osteoarthritis grade. However, 24 hips (12.6\%) deteriorated to a more severe grade, and $11(5.8 \%)$ of those hips progressed to end-stage osteoarthritis (MD group: Table 3; SD group: Table 4). Of these 11, eight were in the MD group and the remaining three were in the SD group. Three of the eight end-stage osteoarthritic hips in the MD group progressed to require THA, whereas none of the hips in the SD group required that level of intervention. The number of hips in each osteoarthritis stage did not differ between the two groups ( $\mathrm{p}=0.4815-0.7505)$.

There were no complications specifically associated with the SD hips (Table 5). The complications in our patients included intraoperative fracture of the posterior column in one hip in the MD group, ectopic bone formation in one hip in both groups, asymptomatic superior limb of a pubis nonunion in one hip in both groups, inferior limb of a pubis fracture in five hips in the MD group and in two hips in the SD group, and ischial fracture in one hip in the MD group. There were no occurrences of infection, avascular necrosis, and femoral or sciatic nerve injury. Although neuropathy of the lateral femoral cutaneous nerve frequently occurred after CPO, it typically healed within a few months. Patients either reported complete recovery of sensation or mild hypesthesia that rarely constituted an obstacle to daily life.

Table 3. Severity of osteoarthritis in the MD group ( $\mathrm{n}=147$ hips)

\begin{tabular}{lll}
\hline $\begin{array}{l}\text { Tönnis } \\
\text { grade }\end{array}$ & $\begin{array}{l}\text { Number of preoperative hips } \\
\text { (number of postoperative hips } \\
\text { with Tönnis Grades 1/2/3/4) }\end{array}$ & $\begin{array}{l}\text { Number of } \\
\text { postoperative } \\
\text { hips }\end{array}$ \\
\hline 1 & $41(36 / 4 / 1 / 0)$ & 37 \\
2 & $77(1 / 70 / 4 / 2)$ & 77 \\
3 & $29(0 / 3 / 20 / 6)$ & 25 \\
4 & 0 & 8 \\
\hline
\end{tabular}

$\mathrm{MD}=$ moderately dysplastic.

Table 4. Severity of osteoarthritis in the SD group ( $n=44$ hips)

\begin{tabular}{lll}
\hline $\begin{array}{l}\text { Tönnis } \\
\text { grade }\end{array}$ & $\begin{array}{l}\text { Number of preoperative hips } \\
\text { (number of postoperative hips } \\
\text { with Tönnis Grades 1/2/3/4) }\end{array}$ & $\begin{array}{l}\text { Number of } \\
\text { postoperative } \\
\text { hips }\end{array}$ \\
\hline 1 & $12(10 / 2 / 0 / 0)$ & 10 \\
2 & $20(0 / 17 / 2 / 1)$ & 22 \\
3 & $12(0 / 3 / 7 / 2)$ & 9 \\
4 & 0 & 3 \\
\hline
\end{tabular}

$\mathrm{SD}=$ severely dysplastic. 
Table 5. Complications

\begin{tabular}{|c|c|c|c|}
\hline Complication & $\begin{array}{l}\text { MD group } \\
(\mathrm{n}=147)\end{array}$ & $\begin{array}{l}\text { SD group } \\
(\mathrm{n}=44)\end{array}$ & $\begin{array}{l}\text { Total } \\
(\mathrm{n}=191)\end{array}$ \\
\hline \multicolumn{4}{|c|}{ Intraoperative complications (number of hips) } \\
\hline $\begin{array}{l}\text { Fracture of the posterior } \\
\text { column }\end{array}$ & 1 & 0 & 1 \\
\hline $\begin{array}{l}\text { Femoral nerve or sciatic } \\
\text { nerve injury }\end{array}$ & 0 & 0 & 0 \\
\hline Blood vessel injury & 0 & 0 & 0 \\
\hline \multicolumn{4}{|c|}{ Postoperative complications (number of hips) } \\
\hline Deep infection & 0 & 0 & 0 \\
\hline $\begin{array}{l}\text { Acetabular or femoral head } \\
\text { necrosis }\end{array}$ & 0 & 0 & 0 \\
\hline $\begin{array}{l}\text { Anterior superior iliac spine } \\
\text { nonunion }\end{array}$ & 0 & 0 & 0 \\
\hline $\begin{array}{l}\text { Ilium delayed union or } \\
\text { nonunion }\end{array}$ & 0 & 0 & 0 \\
\hline Ectopic bone formation & 1 & 1 & 2 \\
\hline $\begin{array}{l}\text { Asymptomatic superior limb } \\
\text { of pubis nonunion }\end{array}$ & 1 & 1 & 2 \\
\hline Inferior limb of pubis fracture & 5 & 2 & 7 \\
\hline Ischial fracture & 1 & 0 & 1 \\
\hline
\end{tabular}

$\mathrm{MD}=$ moderately dysplastic; $\mathrm{SD}=$ severely dysplastic.

\section{Discussion}

Periacetabular osteotomy is a well-established surgical treatment for early stages of osteoarthritis caused by dysplastic hips. At our institution, if excellent joint congruency was identified on the preoperative AP radiograph of the hip at maximum abduction, SD hips with $\mathrm{CE}$ angles less than $0^{\circ}$ classified as Severin Group IV-b were indicated for a $\mathrm{CPO}$ without using additional techniques. In a CPO [15, $21]$, the curvilinear $\mathrm{C}$-shaped osteotomy makes it easy to move and reposition the acetabular fragment and does not result in a large gap at the osteotomy surface. Furthermore, it is not necessary to expose the joint capsule by detaching the gluteus minimus and rectus femoris muscles, so no incisions are made outside of the pelvis. We compared the results of CPO alone in the treatment of SD and MD hips.

We acknowledge several limitations to this study. The first is the retrospective nature of our study. Second, we cannot predict the long-term failure rate because the followup period was relatively short and not uniform for all patients. Third, the number of patients having subluxated hips classified as Severin Group IV-b was small compared with those having MD hips classified as Severin Groups III and IV-a. However, the gender proportion, mean age at $\mathrm{CPO}$, and mean duration of followup were not different between the two groups. Fourth, we defined SD hips as Severin Group IV-b, in accordance with previous research $[3,4,16-19]$. However, the mean preoperative CE angle of our subluxated hips with Severin Group IV-b $\left(-6^{\circ}\right)$ was small compared with those reported in other studies $\left(-11^{\circ}\right.$ to $-21.1^{\circ}$ ), which included dislocated hips classified as Severin Group V. We did not have much experience using periacetabular osteotomy for the treatment of Severin Group V dislocated hips. Therefore, we could not investigate the treatment of Severin Group V hips and cannot compare our data with data from other studies.

Although the mean postoperative $\mathrm{CE}$ angle and $\mathrm{AHI}$ in the SD group were slightly less than those in the MD group, the mean postoperative ARO (MD group: $7.0^{\circ}, \mathrm{SD}$ group: $8.3^{\circ}$ ) and HLI (MD group: $57.6 \%$, SD group: $58.4 \%$ ) did not differ between the two groups. In previous studies, the mean AROs of normal male and female hips [16] were $4.6^{\circ}$ and $5.6^{\circ}$, respectively. Studies of other osteotomy techniques showed the mean postoperative ARO was $2.9^{\circ}$ to $12.8^{\circ}$, and the mean postoperative HLI was $25.6 \%$ to $72.3 \%$ [2, 3, 11, 16, 17, 19, 25]. Our study showed using CPO for treatment of SD hips classified as Severin Group IV-b with preoperative CE angles as low as $-20^{\circ}$ could restore the weightbearing area and medialization without the use of additional techniques (bone grafting at the osteotomy site of the ilium, release of the joint capsule, and adductor tenotomy). We believe CPO without any other procedures can restore almost all cases of SD hips classified as Severin Group IV-b. Operations for dysplastic hips classified as Severin Group V may require additional techniques to restore hip congruency, such as bone grafting, release of the joint capsule, adductor tenotomy, or osteotomy of the proximal femur, to restore hip congruency.

Regardless of the preoperative severity of the dysplastic hips, the majority of hips (87.4\%) receiving CPO maintained their preoperative Tönnis osteoarthritis grade. However, some hips showed osteoarthritis grade progression in both groups and required careful followup.

No complications particular to the SD hips were identified. In previous reports, serious complications, such as motor nerve palsy [5, 20], deep infection [11], necrosis of the femoral head or acetabulum $[1,20]$, and delayed union or nonunion of the ilium $[1,10,13,14,20]$, were observed. However, such major complications did not occur in our series. Although it was assumed nonunion of the superior limb of the pubis would occur mainly in SD hips as a result of a large transfer of the acetabular fragment, this complication also occurred in MD hips. Although it is difficult to reach a clear conclusion owing to the small number of cases, it may be attributable to overcorrection or lateralization producing a large gap in the osteotomy site of the pubis. Since 2005 , we have performed pubic osteotomies using an inclination of $30^{\circ}$ to the horizontal line [21]. The advantages of this method are not only medialization of the femoral head and easy rotation of an acetabular fragment 
but also the possibility of preventing a nonunion so that the osteotomy site has a large contact area. Although the patients with nonunion of the superior ramus of the pubis were asymptomatic throughout the followup period, continued assessment is required. Stress fractures are thought to arise when the load transmission occurs only through the inferior limb of the pubis and ischium [6]. Fractures of the inferior limbs of the pubis were identified in seven (3.7\%) among all the hips. Although the patients with stress fractures had complaints of pain in the buttocks or groin, the progression was denoted as a general pubic bone fracture. After resting, all hips with a fracture of the inferior limb of the pubis showed union, and the pain disappeared without special treatment by the most recent followup.

Good clinical results and low complication rates were obtained by performing a CPO alone for the treatment of SD hips classified as Severin Group IV-b and for MD hips classified as Severin Groups III and IV-a. This study showed CPO alone for treatment of SD hips classified as Severin Group IV-b with preoperative CE angles of as low as $-20^{\circ}$ restored the weightbearing area and medialization.

Acknowledgments We thank Dr. Takeshi Teratani and Dr. Akinori Takeyama for their invaluable advice during the course of this study.

\section{References}

1. Biedermann R, Donnan L, Gabriel A, Wachter R, Krismer M, Behensky H. Complications and patient satisfaction after periacetabular pelvic osteotomy. Int Orthop. 2008;32:611-617.

2. Chiari K. Medial displacement osteotomy of the pelvis. Clin Orthop Relat Res. 1974;98:55-71.

3. Clohisy JC, Barrett SE, Gordon JE, Delgado ED, Schoenecker PL. Periacetabular osteotomy for the treatment of severe acetabular dysplasia. J Bone Joint Surg Am. 2005;87:254-259.

4. Clohisy JC, Barrett SE, Gordon JE, Delgado ED, Schoenecker PL. Periacetabular osteotomy in the treatment of severe acetabular dysplasia: surgical technique. J Bone Joint Surg Am. 2006; 88(suppl 1):65-83.

5. Davey JP, Santore RF. Complications of periacetabular osteotomy. Clin Orthop Relat Res. 1999;363:33-37.

6. Espinosa N, Strassberg J, Belzile EL, Millis MB, Kim YJ. Extraarticular fractures after periacetabular osteotomy. Clin Orthop Relat Res. 2008;466:1645-1651.

7. Ganz R, Klaue K, Vinh TS, Mast JW. A new periacetabular osteotomy for the treatment of hip dysplasias: technique and preliminary results. Clin Orthop Relat Res. 1988;232:26-36.

8. Harris WH. Traumatic arthritis of the hip after dislocation and acetabular fractures: treatment by mold arthroplasty. An endresult study using a new method of result evaluation. J Bone Joint Surg Am. 1969;51:737-755.
9. Heyman $\mathrm{CH}$, Herndon $\mathrm{CH}$. Legg-Perthes disease: a method for the measurement of the roentgenographic result. J Bone Joint Surg Am. 1950;32:767-778.

10. Hussell JG, Mast JW, Mayo KA, Howie DW, Ganz R. A comparison of different surgical approaches for the periacetabular osteotomy. Clin Orthop Relat Res. 1999;363:64-72.

11. Ito H, Matsuno T, Minami A. Rotational acetabular osteotomy through an Ollier lateral U approach. Clin Orthop Relat Res. 2007;459:200-206.

12. Massie WK, Howorth MB. Congenital dislocation of the hip. Part I: Method of grading results. J Bone Joint Surg Am. 1950; 32:519-531.

13. Matta JM, Stover MD, Siebenrock K. Periacetabular osteotomy through the Smith-Petersen approach. Clin Orthop Relat Res. 1999;363:21-32.

14. Murphy SB, Millis MB. Periacetabular osteotomy without abductor dissection using direct anterior exposure. Clin Orthop Relat Res. 1999;364:92-98.

15. Naito M, Shiramizu K, Akiyoshi Y, Ezoe M, Nakamura Y. Curved periacetabular osteotomy for treatment of dysplastic hip. Clin Orthop Relat Res. 2005;433:129-135.

16. Ninomiya S. Rotational acetabular osteotomy for the severely dysplastic hip in the adolescent and adult. Clin Orthop Relat Res. 1989;247:127-137.

17. Nozawa M, Shitoto K, Hirose T, Matsuda K, Michino K, Kajihara H, Maezawa K, Kurosawa H. Rotational acetabular osteotomy for severely dysplastic acetabulum. Arch Orthop Trauma Surg. 2000;120:376-379.

18. Severin E. Contribution to the knowledge of congenital dislocation of the hip joint: late results of closed reduction and arthrographic studies of recent cases. Acta Chir Scand. 1941;84(suppl 63): $37-54$.

19. Shindo H, Igarashi H, Taneda H, Azuma H. Rotational acetabular osteotomy for severe dysplasia of the hip with a false acetabulum. J Bone Joint Surg Br. 1996;78:871-877.

20. Siebenrock KA, Schöll E, Lottenbach M, Ganz R. Bernese periacetabular osteotomy. Clin Orthop Relat Res. 1999;363:9-20.

21. Teratani T, Naito M, Shiramizu K, Nakamura Y, Moriyama S. Modified pubic osteotomy for medialization of the femoral head in periacetabular osteotomy: a retrospective study of 144 hips. Acta Orthop. 2008;79:474-482.

22. Tönnis D. Clinical and radiographic schemes for evaluating therapeutic results, Chapter 13. In: Congenital Dysplasia and Dislocation of the Hip in Children and Adults. New York, NY: Springer-Verlag; 1987:165-171.

23. Ward WT, Vogt M, Grudziak JS, Tumer Y, Cook PC, Fitch RD. Severin classification system for evaluation of the results of operative treatment of congenital dislocation of the hip: a study of intraobserver and interobserver reliability. J Bone Joint Surg Am. 1997;79:656-663.

24. Wiberg G. Studies on dysplastic acetabula and congenital subluxation of the hip joint: with special reference to the complication of osteoarthritis. Acta Chir Scand. 1939;83(suppl 58): 7-38.

25. Yasunaga Y, Takahashi K, Ochi M, Ikuta Y, Hisatome T, Nakashiro J, Yamamoto S. Rotational acetabular osteotomy in patients forty-six years of age or older: comparison with younger patients. J Bone Joint Surg Am. 2003;85:266-272. 